\title{
The effect of prehospital tranexamic acid on outcome in polytrauma patients with associated severe brain injury
}

\author{
Karlijn J. P. van Wessem ${ }^{1}\left[\right.$ ( ) Denise Jochems ${ }^{1} \cdot$ Luke P. H. Leenen $^{1}{ }^{1}$
}

Received: 11 August 2021 / Accepted: 1 November 2021 / Published online: 14 November 2021

(c) The Author(s), under exclusive licence to Springer-Verlag GmbH Germany 2021

\begin{abstract}
Introduction Tranexamic acid (TXA) has shown to be beneficial in selected patients with hemorrhagic shock. Recently, TXA has gained interest in isolated traumatic brain injury (TBI) patients with variable results. There are limited data on TXA in polytrauma with associated TBI. This study investigated the role of TXA in severely injured patients with associated severe TBI.

Methods A 7.5-year prospective cohort study was performed to investigate the relation between prehospital TXA and mortality in consecutive trauma patients with associated severe TBI (Abbreviated Injury Scale (AIS)head $\geq 3$ ) admitted to a Level-1 Trauma Center ICU. Indication for prehospital TXA administration was (suspicion of) hemorrhagic shock, and/ or systolic blood pressure (SBP) $\leq 90 \mathrm{mmHg}$. Demographics, data on physiology, resuscitation, and outcomes were prospectively collected.

Results Two hundred thirty-four patients (67\% males) with median age of 49 years and ISS 33 (98\% blunt injuries) were included. Thirteen patients $(6 \%)$ developed thromboembolic complications; mortality rate was $24 \%$. Fifty-one percent of patients received prehospital TXA. TXA patients were younger, had more deranged physiology on arrival, and received more crystalloids and blood products $\leq 24 \mathrm{~h}$. There was, however, no difference in overall outcome between TXA patients and no-TXA patients.

Conclusions Despite having a more deranged physiology TXA patients had similar outcome compared to no-TXA patients who were much older. Thromboembolic complication rate was low. Prehospital tranexamic acid has no evident effect on outcome in polytrauma patients with associated critical brain injury.
\end{abstract}

Keywords Tranexamic acid $\cdot$ Polytrauma $\cdot$ TBI $\cdot$ Morbidity $\cdot$ Mortality

\begin{tabular}{llll} 
Abbreviations & FFP & Fresh frozen plasma \\
AIS & Abbreviated injury scale & GCS & Glasgow coma score \\
ARDS & Adult respiratory distress syndrome & Hb & Hemoglobin \\
ATLS & Advanced trauma life support & H-LOS & Hospital length of stay \\
BD & Base deficit & ICU & Intensive care unit \\
CRASH & Clinical randomization of an anti-fibrinolytic in & ISS & Injury severity score \\
& significant hemorrhage & IQR & Interquartile range \\
ED $\quad$ Emergency department & LOS & Length of stay \\
& MODS & Multiple organ dysfunction syndrome \\
\hline Karlijn J. P. van Wessem & MOF & Multiple organ failure \\
kwessem @umcutrecht.nl & MOI & Mechanism of injury \\
Denise Jochems & OR & Operating room \\
D.Jochems-2@umcutrecht.nl & PaC02 & Partial pressure of carbon dioxide in arterial \\
Luke P. H. Leenen & & blood \\
L.P.H.Leenen@umcutrecht.nl & PLT & Platelets \\
1 Department of Trauma Surgery, University Medical & PRBC & Packed red blood cells \\
Center Utrecht, Heidelberglaan 100, 3584 CX Utrecht, & PT & Prothrombin time \\
The Netherlands & SBP & Systolic blood pressure
\end{tabular}


TBI Traumatic brain injury

TXA Tranexamic acid

\section{Introduction}

Traumatic brain injury (TBI) has become the leading cause of death after trauma in the western world [1]. Death by TBI is often caused by acute intracranial bleeding which often continues for several hours after injury. Ongoing intracranial bleeding can lead to raised intracranial pressure, brain herniation, and death [2]. Tranexamic acid (TXA) reduces bleeding by inhibiting fibrinolysis [3]. The Clinical Randomization of an Antifibrinolytic in Significant Hemorrhage 2 (CRASH-2) trial showed that early administration of TXA in adults who had either significant hemorrhage, hypotension, or who were considered to be at risk of significant hemorrhage after injury resulted in significant improvement in (hemorrhage-caused) mortality [4]. These results have led to liberal TXA administration in trauma patients with hemorrhagic shock. Since TXA might also be beneficial to TBI patients with intracranial bleeds, a sub-analysis of CRASH-2 trial was performed investigating the role of TXA in isolated TBI. These data showed a non-significant reduction in hemorrhage growth, fewer focal ischemic lesions, and fewer deaths [5]. The subsequent CRASH-3 trial including adults with isolated TBI who were randomized to either TXA or placebo showed a reduced head injury-related death in patients with mild to moderate TBI who received TXA within $3 \mathrm{~h}$ after injury [6]. This reduced mortality risk, however, was not demonstrated in patients with severe head injury [6]. Additionally, pooled CRASH-2 and CRASH-3 trial data showed that TXA reduced early deaths in non-moribund TBI patients regardless of TBI severity [7]. In contrast, several other studies showed no improvement in survival nor in neurologic outcome in patients with moderate to severe TBI although some studies reported a reduction in progression of intracranial hemorrhage after TXA [8-12]. A recent study showed even an increased mortality in patients with severe isolated TBI if TXA was prehospitally administered [13].

In literature, most studies on TXA focused either on patients in hemorrhagic shock or on patients with isolated TBI. In our hospital the vast majority of severely injured patients die of associated traumatic brain injury [1]. Therefore, we conducted a retrospective analysis of prospectively collected data of polytrauma patients with associated moderate to severe TBI to investigate whether prehospital TXA administration would have an influence on mortality. We hypothesized that TXA administration was not related to mortality.

\section{Materials and methods}

\section{Study setting}

From November 2013, a 7.5-year prospective populationbased cohort study was undertaken to investigate outcomes in severely injured patients admitted to the Intensive Care Unit (ICU) of a major (Level-1) trauma center. Details of the hospital and catchment area were previously described [14]. All consecutive polytrauma patients with associated severe TBI (AIS head $\geq 3$ ) who were admitted to the adult ICU were included. Severe TBI was defined as being serious (AIS head 3), severe (AIS head 4), or critical (AIS head 5) [10]. Patients with associated AIS head 6 were excluded since these injuries are generally regarded as unsurvivable. Patients who had AIS head scores based on isolated C-spine injuries were excluded as well since the natural history, pathology, and potential impact of these injuries are likely different from true TBI injuries.

ICU admission could be either directly from the emergency department (ED) or postoperatively from the operating room (OR) after urgent surgery. A flowchart of patient inclusion is shown in Fig. 1.

\section{Data collection}

All data were prospectively collected by authors KW and LL and included demographics, shock, and resuscitation parameters. Crystalloid and blood products administration, including Packed Red Blood Cells (PRBC), Fresh Frozen Plasma (FFP), and Platelets (PLT), was documented in the first $24 \mathrm{~h}$ after admission. Additionally, prehospital administration of tranexamic acid (TXA) was recorded. Our prehospital protocol recommends administering TXA within $3 \mathrm{~h}$ of injury for signs of the presence of impending hemorrhagic shock, hypotension (systolic blood pressure $\leq 90 \mathrm{mmHg}$ ), and/or clinical suspicion of major hemorrhage. Prehospital TXA dosage was $1 \mathrm{~g}$ bolus; $1 \mathrm{~g}$ infusion was repeated over $8 \mathrm{~h}$ at discretion of the treating surgeon, anesthesiologist, and/or intensivist. In our hospital TXA is not routinely used in (suspicion of) isolated TBI.

Denver MOF scores [15] and ARDS Berlin criteria [16] were registered daily up until 28 days or discharge from ICU. Primary outcome was the relation between prehospital TXA administration and in-hospital mortality in severely injured patients with associated severe TBI. Secondary outcome was the relation between prehospital TXA and complications, such as inflammatory (ARDS, MODS), thromboembolic, and/or infectious complications. 
Fig. 1 Flowchart of included patients

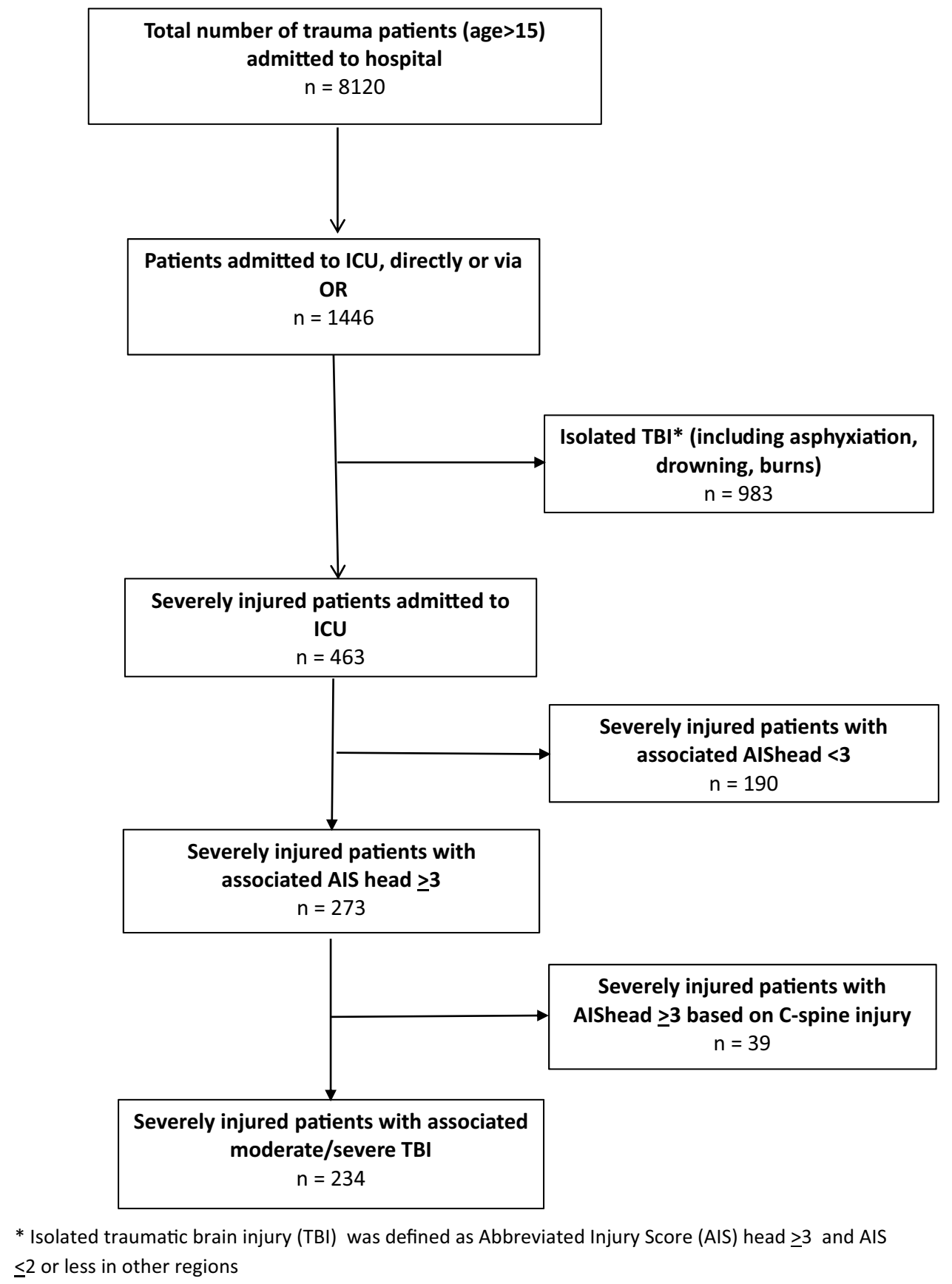

\section{Ethical approval}

The local ethics committee approved this prospective observational study and waived consent (reference number WAG/ $\mathrm{mb} / 16 / 026664)$.

\section{Statistical analysis}

All statistical analysis was performed using IBM SPSS Statistics, version 25.0 (Armonk, NY, USA). Results are presented as median and interquartile range (IQR). Kruskal-Wallis was used to test continuous variables for equality between patients who received TXA and patients who did not. Categorical data were tested with either Chisquare or Fisher's exact test based on the number of patients (values less than 6). Variables with univariate statistical significance of less than 0.10 were included in a multivariate logistic regression analysis to identify independent risk factors for mortality and are presented as odds ratios and 95\% confidence intervals. Kaplan-Meier curves with log rank 
(Mantel-Cox) test were used to calculate 30-day survival. Statistical significance was defined as $P<0.05$.

\section{Results}

\section{Demographics}

Two hundred thirty-four severely injured patients $(67 \%$ male) with a median age of 49 (28-63) years who were admitted to ICU were included. Ninety-eight percent of injuries $(n=231)$ were caused by a blunt mechanism, $63 \%$ $(n=147)$ was prehospitally intubated, and median ISS was 33 (27-38) with most severe injuries located in the brain (Abbreviated Injury Scale (AIS) head 4 (3-4) and chest (AIS chest $3(2-4)$ ). Thirty-eight patients (16\%) underwent an urgent laparotomy. Physiology, resuscitation and outcome data are presented in Table 1.

Fifty-one percent of patients $(n=120)$ received prehospital TXA. Median prehospital time was 1:01 (0:57-1:09) h. Consequently, prehospital TXA was administered within an hour after injury. Patients who received prehospital TXA were younger, more often prehospitally intubated, and underwent more often an urgent laparotomy (Table 1). Further, they were more acidotic with higher $\mathrm{PaCO} 2$, and lower hemoglobin $(\mathrm{Hb})$ in ED. They received more crystalloids and blood products $\leq 24 \mathrm{~h}$ than patients who did not receive prehospital TXA. There was, however, no difference in outcome between TXA and no-TXA patients (Table 1). In patients with SBP $\leq 90 \mathrm{mmHg}$ on arrival in ED there was also no difference in outcome between TXA and no-TXA patients (supplemental Table S1).

Fifty-seven (24\%) patients died: Fifty ( $88 \%$ ) of them died of TBI, 4 (7\%) died of respiratory insufficiency, $1(2 \%)$ died of cardiac origin, $1(2 \%)$ due to MODS, and $1(2 \%)$ due to sepsis. Median time to in-hospital death was 7 (3-12) days; only 2 patients died later than 30 days after admission (43 and 120 days, respectively). Patients who died were older, more severely injured (mostly more severe brain injury), and had worse physiology with lower $\mathrm{Hb}$ on arrival in ED. Further, they received more crystalloids and blood products in the first $24 \mathrm{~h}$ after admission. TXA was not related to death. Patients who survived stayed longer in ICU and in hospital and developed more often infectious complications (Table 2). In multivariate analysis only age and AIS head were independent predictors for mortality (Table 3).

\section{Sub-analysis per traumatic brain injury severity}

When comparing polytrauma patients per brain injury severity (AIS head 3-5), there was (besides the difference in ISS) no difference in demographics, physiology, resuscitation parameters nor in ventilator days, ICU-LOS, or H-LOS between the 3 groups. Polytrauma with AIS head 3 developed most often thromboembolic complications, but died less frequently than patients with AIS head 4 or AIS head 5 (Table 4). TBI was the cause of death in all AIS head 5 patients compared to $81 \%$ in AIS head 4 , and $67 \%$ in AIS head 3 ( $p=0.06$, supplemental Table S2).

When analyzing prehospital TXA administration and mortality per AIS head classification, no significant difference between TXA and mortality between AIS head groups was observed ( $p=0.40$, Table S3).

Figure 2 shows the relation between prehospital TXA administration and 30-day mortality in polytrauma patients with associated AIS head 3 to 5. There was no difference in survival between TXA and no-TXA patients. Also, there was no difference in 30-day mortality within separate AIS head groups (Fig. 2).

\section{Discussion}

In this cohort of polytrauma patients with associated severe to critical TBI, there was no difference in outcome between patients who received prehospital TXA and those who did not even though TXA patients had a more deranged physiology. This could potentially be interpreted as improved outcome by TXA. However, this should be concluded with caution since none of the patients died of hemorrhage; moreover, if only patients with $\mathrm{SBP} \leq 90 \mathrm{mmHg}$ in ED were analyzed, there was no difference in morbidity and mortality between patients with and without TXA. Further, patients without TXA did as well as TXA patients despite being 11 years older. This is particularly interesting since age was an independent predictor for mortality in multivariate analysis and physiologic parameters were not.

When analyzing TBI severity in the various subgroups, there was no difference in physiology between the groups, although there was an increased mortality with increasing AIS head. This was confirmed by the fact that AIS head was the largest independent predictor for mortality. There was no difference in 30-day mortality in patients with and without prehospital TXA in the whole population, nor in sub-analysis with patients with associated AIS head 3 to 5 .

Despite the fact that TXA patients had a more deranged physiology on arrival, there was no difference in outcome, which could be possibly explained by the fact that prehospital transport times in our region are short with prompt resuscitation making the beneficial effects of TXA smaller compared to regions with long transport times and limited resources.

The results of this study are in line with CRASH2-Intracranial Bleeding Study (IBS), a sub-analysis of 
Table 1 Demographics in polytrauma patients with associated severe traumatic brain injury (AIS head 3-5)

\begin{tabular}{|c|c|c|c|c|}
\hline & Total population $(n=234)$ & Prehospital TXA $(n=120)$ & $\begin{array}{l}\text { No prehospital TXA } \\
(n=114)\end{array}$ & $P$ value \\
\hline Age (years) & $49(28-63)$ & $42(23-59)$ & $53(33-65)$ & $0.007 *$ \\
\hline Male gender & $157(67)$ & $80(67)$ & 77 (68) & 0.89 \\
\hline Blunt MOI & $230(98)$ & $118(98)$ & $112(98)$ & 1.0 \\
\hline Prehospital intubation & $147(63)$ & $96(79)$ & $51(45)$ & $<0.001^{*}$ \\
\hline Urgent laparotomy & $38(16)$ & $26(22)$ & $12(11)$ & $0.02 *$ \\
\hline ISS & $33(27-38)$ & $34(27-41)$ & $29(25-38)$ & 0.06 \\
\hline AIS head & $4(3-4)$ & $4(3-4)$ & $4(3-5)$ & 0.51 \\
\hline AIS face & $1(0-2)$ & $0(0-2)$ & $1(0-2)$ & 0.52 \\
\hline AIS chest & $3(2-4)$ & $3(2-4)$ & $3(2-3)$ & 0.35 \\
\hline AIS abdomen & $0(0-2)$ & $0(0-2)$ & $0(0-2)$ & 0.37 \\
\hline AIS pelvis/extremities & $2(1-3)$ & $2(2-3)$ & $2(0-3)$ & 0.13 \\
\hline AIS external & $0(0-1)$ & $0(0-1)$ & $0(0-1)$ & 0.91 \\
\hline SBP_ED $(\mathrm{mmHg})$ & $123(101-142)$ & $120(100-140)$ & $127(102-150)$ & 0.07 \\
\hline $\mathrm{SBP} \leq 90 \mathrm{mmHg} \_\mathrm{ED}$ & $38(16)$ & $23(19)$ & $15(13)$ & 0.29 \\
\hline $\mathrm{Hb}$ ED $(\mathrm{mmol} / \mathrm{L})$ & $8.0(7.2-8.9)$ & $7.6(7.0-8.4)$ & $8.2(7.8-9.1)$ & $0.001^{*}$ \\
\hline pH_ED & $7.31(7.24-7.36)$ & $7.29(7.21-7.35)$ & $7.34(7.28-7.38)$ & $<0.001^{*}$ \\
\hline PaC02_ED (mmHg) & $46(42-53)$ & $48(43-56)$ & $45(39-49)$ & $<0.001 *$ \\
\hline $\mathrm{BD} \_\mathrm{ED}(\mathrm{mmol} / \mathrm{L})$ & $-3.0(-6.0-0.0)$ & $-3.0(-7.0-1.0)$ & $-2.0(-5.0-0.0)$ & $0.04 *$ \\
\hline PT_ED (sec) & $14.4(12.9-16.4)$ & $14.6(13.0-17.5)$ & $14.1(12.5-15.7)$ & 0.06 \\
\hline \multicolumn{5}{|l|}{ Resuscitation parameters } \\
\hline Crystalloids $\leq 24 \mathrm{~h}(\mathrm{~L})$ & $7.2(5.0-10.0)$ & $7.9(5.7-10.7)$ & $6.1(4.4-8.6)$ & $0.001^{*}$ \\
\hline $\mathrm{PRBC} \leq 24 \mathrm{~h}(\mathrm{U})$ & $0(0-4)$ & $2(0-4)$ & $0(0-4)$ & $0.002 *$ \\
\hline $\mathrm{PRBC} \geq 10$ units $\leq 24 \mathrm{~h}$ & $19(8)$ & $14(12)$ & $5(4)$ & 0.05 \\
\hline $\mathrm{FFP} \leq 24 \mathrm{~h}(\mathrm{U})$ & $0(0-4)$ & $0(0-5)$ & $0(0-3)$ & $0.02 *$ \\
\hline $\mathrm{PLT} \leq 24 \mathrm{~h}(\mathrm{U})^{\#}$ & $0(0-1)$ & $0(0-1)$ & $0(0-0)$ & $0.02 *$ \\
\hline \multicolumn{5}{|l|}{ Outcome parameters } \\
\hline Ventilator days & $7(3-12)$ & $7(3-12)$ & $6(2-12)$ & 0.59 \\
\hline Ventilator free days & $12(1-19)$ & $13(1-19)$ & $12(3-19)$ & 0.93 \\
\hline ICU LOS (days) & $8(3-14)$ & $8(3-15)$ & $8(3-14)$ & 0.62 \\
\hline H-LOS (days) & $20(10-34)$ & $20(9-36)$ & $20(11-33)$ & 0.59 \\
\hline MODS & $36(15)$ & $19(16)$ & $17(15)$ & 0.86 \\
\hline ARDS & $5(2)$ & $3(3)$ & $2(2)$ & 1.0 \\
\hline Infectious complications & $98(42)$ & $49(41)$ & $49(43)$ & 0.79 \\
\hline Thromboembolic complications & $13(6)$ & $6(5)$ & $7(6)$ & 0.78 \\
\hline GOS at discharge & $3(1-3)$ & $3(1-3)$ & $3(2-3)$ & 0.40 \\
\hline Mortality & $57(24)$ & $32(27)$ & $25(22)$ & 0.45 \\
\hline
\end{tabular}

Data are expressed in median (IQR) or absolute numbers (\%)

$M O I$ mechanism of injury, ISS injury severity score, $A I S$ abbreviated injury scale, $E D$ emergency department, $S B P$ systolic blood pressure, $H b$ hemoglobin, $\mathrm{PaCO} 2$ partial pressure of carbon dioxide in arterial blood, $B D$ base deficit, $P T$ prothrombin time, $P R B C$ packed red blood cells, FFP fresh frozen plasma, PLT platelets, ICU intensive care unit, $L O S$ length of stay, $H$-LOS hospital length of stay, MODS multiple organ dysfunction syndrome, ARDS adult respiratory distress syndrome, GOS Glasgow outcome score

* = statistically significant

${ }^{\#} 1$ unit of platelets contains 5 donors

CRASH-2 in which 270 patients were included who also suffered from TBI (which was defined a GCS $\leq 14$ and CT head abnormalities compatible with TBI) that also showed no statistical difference in mortality [5]. The
CRASH-2 study, however, also included mild and moderate TBI patients and is therefore not fully comparable to our study population in which only patients with AIS head $\geq 3$ were included. Several other studies on isolated 
Table 2 Comparison of patients who survived and who did not

\begin{tabular}{|c|c|c|c|}
\hline & Survival $(n=177)$ & Deceased $(n=57)$ & $P$ value \\
\hline Age (years) & $46(28-59)$ & $56(32-73)$ & $0.01 *$ \\
\hline Male gender & $119(67)$ & $38(67)$ & 1.0 \\
\hline Blunt MOI & $174(98)$ & $56(98)$ & 1.0 \\
\hline Prehospital intubation & $106(60)$ & $41(72)$ & 0.12 \\
\hline ISS & $29(26-36)$ & $38(29-44)$ & $<0.001 *$ \\
\hline AIS head & $4(3-4)$ & $4(4-5)$ & $<0.001 *$ \\
\hline AIS face & $0(0-2)$ & $1(0-2)$ & 0.57 \\
\hline AIS chest & $3(2-3)$ & $3(3-4)$ & 0.11 \\
\hline AIS abdomen & $0(0-2)$ & $0(0-2)$ & $0.02 *$ \\
\hline AIS pelvis/extremities & $2(1-3)$ & $2(2-3)$ & 0.35 \\
\hline AIS external & $0(0-1)$ & $0(0-1)$ & $0.04 *$ \\
\hline Urgent laparotomy & $26(15)$ & $12(21)$ & 0.30 \\
\hline SBP_ED $(\mathrm{mmHg})$ & $125(104-142)$ & $120(93-140)$ & 0.19 \\
\hline $\mathrm{SBP} \leq 90$ mmHg_ED & $25(14)$ & $13(23)$ & 0.11 \\
\hline $\mathrm{Hb}$ ED $(\mathrm{mmol} / \mathrm{L})$ & $8.0(7.3-9.0)$ & $7.6(6.5-8.4)$ & $0.04 *$ \\
\hline pH_ED & $7.33(7.27-7.37)$ & $7.24(7.18-7.32)$ & $<0.001 *$ \\
\hline PCO2_ED (mmHg) & $46(41-52)$ & $48(44-56)$ & $0.02 *$ \\
\hline BD_ED (mmol/L) & $-2.0(-5.0-0.0)$ & $-6.0(-9.0-2.0)$ & $<0.001 *$ \\
\hline PT_ED (sec) & $14.0(12.9-15.8)$ & $14.9(12.8-18.5)$ & 0.06 \\
\hline \multicolumn{4}{|l|}{ Resuscitation parameters } \\
\hline Prehospital TXA & $88(50)$ & $32(56)$ & 0.40 \\
\hline Crystalloids $\leq 24 \mathrm{~h}(\mathrm{~L})$ & $6.8(4.5-9.2)$ & $9.0(6.1-12.2)$ & $<0.001^{*}$ \\
\hline $\mathrm{PRBC} \leq 24 \mathrm{~h}(\mathrm{U})$ & $0(0-4)$ & $2(0-6)$ & $0.002 *$ \\
\hline $\mathrm{PRBC} \geq 10$ units $\leq 24 \mathrm{~h}$ & $12(7)$ & $6(11)$ & 0.25 \\
\hline $\mathrm{FFP} \leq 24 \mathrm{~h}(\mathrm{U})$ & $0(0-4)$ & $2(0-5)$ & $0.01 *$ \\
\hline $\mathrm{PLT} \leq 24 \mathrm{~h}(\mathrm{U})^{\#}$ & $0(0-0)$ & $0(0-1)$ & $0.03 *$ \\
\hline \multicolumn{4}{|l|}{ Outcome parameters } \\
\hline Ventilator days & $7(3-12)$ & $6(3-10)$ & 0.32 \\
\hline Ventilator free days & $15(10-20)$ & $0(0-1)$ & $<0.001 *$ \\
\hline ICU LOS (days) & $9(4-15)$ & $7(3-13)$ & $0.02 *$ \\
\hline H-LOS (days) & $26(16-37)$ & $7(3-13)$ & $<0.001 *$ \\
\hline MODS & $25(14)$ & $11(19)$ & 0.35 \\
\hline ARDS & $4(2)$ & $1(2)$ & 1.0 \\
\hline Infectious complications & $84(47)$ & $14(25)$ & $0.002 *$ \\
\hline Thromboembolic complications & $11(6)$ & $2(4)$ & 0.74 \\
\hline
\end{tabular}

Data are expressed in median (IQR) or absolute numbers (\%)

$I S S$ injury severity score, $A I S$ abbreviated injury scale, $E D$ emergency department, $S B P$ systolic blood pressure, $\mathrm{Hb}$ hemoglobin, $\mathrm{PaCO} 2$ partial pressure of carbon dioxide in arterial blood, $B D$ base deficit, $P T$ prothrombin time, TXA tranexamic acid

$*=$ statistically significant
TBI patients also demonstrated no clear beneficial effect of TXA [8-12], although data from subgroup analysis of the meta-analysis by Al Lawati et al. suggested that TXA might decrease hematoma expansion [9]. Data from the CRASH-3 trial that included only patients with isolated TBI demonstrated a beneficial effect of early TXA administration in mild and moderate TBI, but this effect was not observed in patients with severe TBI, which was actually the group of patients of interest in our studied population [6].

Our data are also in contrast with the results in the study by Bossers et al. that showed an increased mortality in isolated severe TBI patients who received prehospital TXA [13]. The results of this study, however, should be 
Table 3 Independent predictors for mortality

\begin{tabular}{llllll}
\hline $\begin{array}{l}\text { Variables in } \\
\text { the equation }\end{array}$ & B coefficient & $P$ value & Odds ratio & \multicolumn{2}{l}{$95 \%$ C.I } \\
\cline { 4 - 6 } & & & & Lower & Upper \\
\hline Age & 0.041 & 0.000 & 1.042 & 1.020 & 1.065 \\
AIS head & 1.282 & 0.000 & 3.603 & 2.119 & 6.125 \\
Hb_ED & -0.016 & 0.260 & 0.984 & 0.956 & 1.012 \\
BD_ED & -0.012 & 0.069 & 0.989 & 0.976 & 1.001 \\
pH_ED & -0.028 & 0.264 & 0.972 & 0.926 & 1.021 \\
Constant & 13.046 & 0.482 & 463329.772 & & \\
\hline
\end{tabular}

$A I S$ abbreviated injury scale, $H b$ hemoglobin, $B D$ base deficit, $E D$ emergency department

interpreted with caution there were some issues regarding confounding by indication and missing data [17].

TXA patients were more often prehospitally intubated with higher $\mathrm{PaCO} 2$ and lower $\mathrm{pH}$. In a previous study we suggested that this relative hypoventilation could be associated with TBI resulting in more often prehospital intubation in TBI patients [18]. This was confirmed by the fact that in this current study $63 \%$ of patients were prehospitally intubated compared to $50 \%$ in a general polytrauma population [18]. Interestingly, there was no relation between prehospital intubation and severity of TBI nor mortality. This suggests that the rationale for prehospital intubation was signs of deranged physiology with associated suspicion of TBI rather than injury severity itself.

In this cohort, patients with serious TBI developed more often thromboembolic complications than severe and critical TBI patients; however, there was no correlation with TXA administration. Numbers were too small to draw substantial conclusions, but it might be partly explained by higher survival rates.

To our knowledge, this is the first prospective cohort study describing the effect of TXA on polytrauma patients with combined severe to critical TBI. The indication for prehospital TXA administration in severely injured patients was suspicion of hemorrhagic shock, a rather liberal criterion, which could lead to unlimited administration of TXA. This liberal approach is confirmed by a previous study on TXA in polytrauma and the fact that half of the studied patients received prehospital TXA even though only $20 \%$ was objectively in shock on arrival in ED [18]. None of the patients died of exsanguination. This could be explained by the fact that patients with both impeding exsanguination and associated severe TBI are likely to be deceased prior to arrival in ED. Based on the current data a liberal attitude regarding prehospital TXA in polytrauma patients with associated critical TBI does not demonstrate negative effects on mortality.

A few limitations need to be acknowledged: First of all, this was a retrospective analysis of a single-center prospective cohort study with its accompanying limits. This includes confounding by indication and this is very difficult to account for. However, it is unlikely that another Randomized Controlled Trial (RCT) the size of CRASH-2 trial will be conducted any time soon. Further, absolute mortality reduction by TXA was low even with more than 20,000 included patients [4]. Despite its limitations a prospective cohort study can add valuable information to that obtained from an RCT and even be as informative as an RCT [19]. Further, one could argue that the number of included patients was fairly low. However, patient numbers from the current study were comparable to the number of included patients in the two other existing studies that included polytrauma with TBI $[5,8]$. Another limitation is the fact that the treating clinicians were also the researchers, and that no details on comorbidities and (anticoagulant) medication nor any data on prehospital and in-hospital Glasgow Coma Scale and pupillary reactivity were collected.

In this study it was decided to investigate the influence of prehospital TXA on outcome in polytrauma patients with associated severe TBI. No data on in-hospital TXA administration were shown to avoid confusion with too many data in one paper. In a previous study we have demonstrated that median time to TXA administration was an hour after injury [18]. This prompt TXA administration makes the division of prehospital versus in-hospital administration of TXA rather arbitrary and the location of TXA administration less relevant than having TXA administered early after injury. This importance of timing rather than geographical location of TXA administration has been highlighted by others as well [20].

In conclusion, in this cohort of polytrauma patients with associated serious to critical TBI TXA patients had similar outcome compared to no-TXA patients despite having a more deranged physiology on arrival in ED, although no-TXA patients were 11 years older. There seems to be no obvious detrimental nor beneficial effect in administering prehospital TXA in polytrauma with associated TBI. 
Table 4 Demographics, physiology, and outcome per AIS head classification

\begin{tabular}{|c|c|c|c|c|}
\hline & AIS head3 $(n=82)$ & AIS head $4(n=96)$ & AIS head $5(n=56)$ & $P$ value \\
\hline Age (years) & $49(29-62)$ & $49(31-65)$ & $47(24-62)$ & 0.68 \\
\hline Male gender & $53(65)$ & $65(68)$ & $39(70)$ & 0.82 \\
\hline Blunt MOI & $80(98)$ & $94(98)$ & $56(100)$ & 0.52 \\
\hline Prehospital intubation & $46(56)$ & $64(67)$ & $37(66)$ & 0.29 \\
\hline Urgent laparotomy & $15(18)$ & $18(19)$ & $5(9)$ & 0.24 \\
\hline ISS & $27(22-34)$ & $31(29-40)$ & $38(35-43)$ & $<0.001 *$ \\
\hline AIS face & $1(0-2)$ & $1(0-2)$ & $0(0-2)$ & 0.30 \\
\hline AIS chest & $3(2-4)$ & $3(3-4)$ & $3(2-3)$ & 0.56 \\
\hline AIS abdomen & $2(0-2)$ & $0(0-2)$ & $0(0-0)$ & 0.05 \\
\hline AIS pelvis/extremities & $2(2-3)$ & $2(1-3)$ & $2(1-3)$ & 0.45 \\
\hline AIS external & $0(0-1)$ & $0(0-1)$ & $0(0-1)$ & 0.06 \\
\hline SBP_ED (mmHg) & $120(104-140)$ & $124(100-142)$ & $129(99-150)$ & 0.17 \\
\hline $\mathrm{SBP} \leq 90 \mathrm{mmHg} \_\mathrm{ED}$ & $11(13)$ & $16(17)$ & $11(20)$ & 0.61 \\
\hline $\mathrm{Hb}$ ED $(\mathrm{mmol} / \mathrm{L})$ & $8.0(7.2-9.1)$ & $8.0(7.3-8.7)$ & $8.2(7.2-9.1)$ & 0.85 \\
\hline pH_ED & $7.32(7.26-7.38)$ & $7.31(7.24-7.36)$ & $7.31(7.23-7.35)$ & 0.42 \\
\hline $\mathrm{PaC02 \_ ED} \mathrm{(mmHg)}$ & $46(39-54)$ & $46(43-52)$ & $48(42-53)$ & 0.13 \\
\hline $\mathrm{BD} \_\mathrm{ED}(\mathrm{mmol} / \mathrm{L})$ & $-3.0(-5.3-0.0)$ & $-2.0(-6.0-1.0)$ & $-3.0(-7.0-0.0)$ & 0.63 \\
\hline PT_ED (sec) & $13.7(12.9-15.3)$ & $14.9(13.3-17.0)$ & $14.4(12.6-16.9)$ & 0.40 \\
\hline \multicolumn{5}{|l|}{ Resuscitation parameters } \\
\hline Prehospital TXA & $46(56)$ & $48(50)$ & $26(46)$ & 0.51 \\
\hline Overall TXA & $55(67)$ & $59(62)$ & $34(61)$ & 0.67 \\
\hline Crystalloids $\leq 24 \mathrm{~h}(\mathrm{~L})$ & $7.0(4.3-10.0)$ & $6.9(5.1-10.4)$ & $7.7(5.5-9.5)$ & 0.44 \\
\hline $\mathrm{PRBC} \leq 24 \mathrm{~h}(\mathrm{U})$ & $0(0-4)$ & $0(0-4)$ & $0(0-4)$ & 0.90 \\
\hline $\mathrm{PRBC} \geq 10$ units $\leq 24 \mathrm{~h}$ & $7(9)$ & $7(7)$ & $4(7)$ & 0.95 \\
\hline $\mathrm{FFP} \leq 24 \mathrm{~h}(\mathrm{U})$ & $0(0-4)$ & $0(0-4)$ & $0(0-4)$ & 0.27 \\
\hline $\mathrm{PLT} \leq 24 \mathrm{~h}(\mathrm{U})^{\#}$ & $0(0-0)$ & $0(0-1)$ & $0(0-1)$ & 0.06 \\
\hline \multicolumn{5}{|l|}{ Outcome parameters } \\
\hline Ventilator days & $5(2-10)$ & $8(5-14)$ & $6(2-10)$ & 0.75 \\
\hline Ventilator free days & $14(8-21)$ & $13(1-20)$ & $2(0-13)$ & 0.33 \\
\hline ICU LOS (days) & $6(3-12)$ & $10(5-16)$ & $6(3-13)$ & 0.11 \\
\hline H-LOS (days) & $20(13-31)$ & $26(12-40)$ & $16(4-28)$ & 0.06 \\
\hline MODS & $10(12)$ & $21(22)$ & $5(9)$ & 0.06 \\
\hline ARDS & $1(1)$ & $4(4)$ & 0 & 0.18 \\
\hline Infectious complications & $32(39)$ & $48(50)$ & $18(32)$ & 0.08 \\
\hline Thromboembolic complications & $9(11)$ & 0 & $4(7)$ & $0.005^{*}$ \\
\hline GOS at discharge & $3(3-4)$ & $3(1-3)$ & $2(1-3)$ & $<0.001^{*}$ \\
\hline Mortality & $6(7)$ & $26(27)$ & $25(45)$ & $<0.001 *$ \\
\hline
\end{tabular}

Data are expressed in median (IQR) or absolute numbers (\%)

$M O I$ mechanism of injury, ISS injury severity score, $A I S$ abbreviated injury scale, $E D$ emergency department, $S B P$ systolic blood pressure, $H b$ hemoglobin, $P a C O 2$ partial pressure of carbon dioxide in arterial blood, $B D$ base deficit, $P T$ prothrombin time, TXA tranexamic acid, $P R B C$ packed red blood cells, FFP fresh frozen plasma, PLT platelets, ICU intensive care unit, LOS length of stay, $H$-LOS hospital length of stay, $M O D S$ multiple organ dysfunction syndrome, $A R D S$ adult respiratory distress syndrome, GOS Glasgow outcome score

$*$ =statistically significant

${ }^{\#} 1$ unit of platelets contains 5 donors 
Fig. 2 A Prehospital tranexamic acid (TXA) administration related to 30-day mortality in polytrauma patients with associated severe to critical TBI. B Prehospital tranexamic acid (TXA) administration related to 30-day mortality in polytrauma patients with associated serious TBI (AIS head 3). C Prehospital tranexamic acid (TXA) administration related to 30-day mortality in polytrauma patients with associated severe TBI (AIS head 4). D Prehospital tranexamic acid (TXA) administration related to 30-day mortality in polytrauma patients with associated critical TBI (AIS head 5)
A

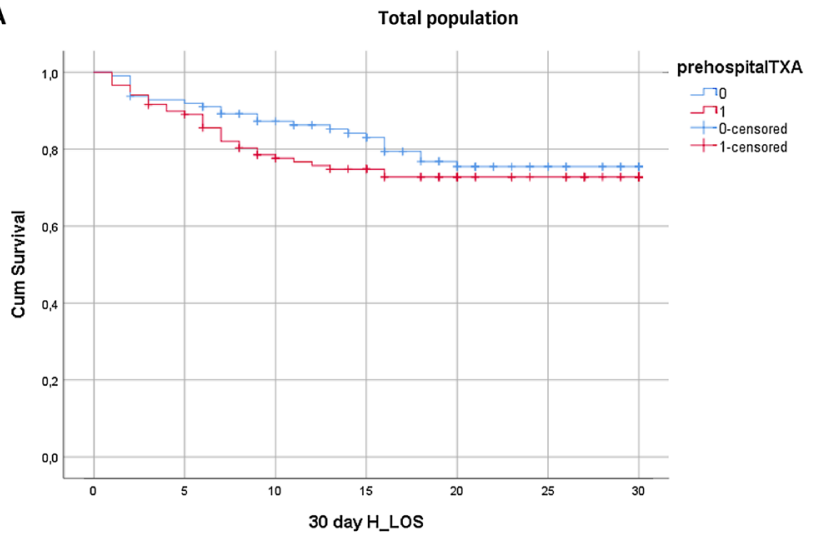

B

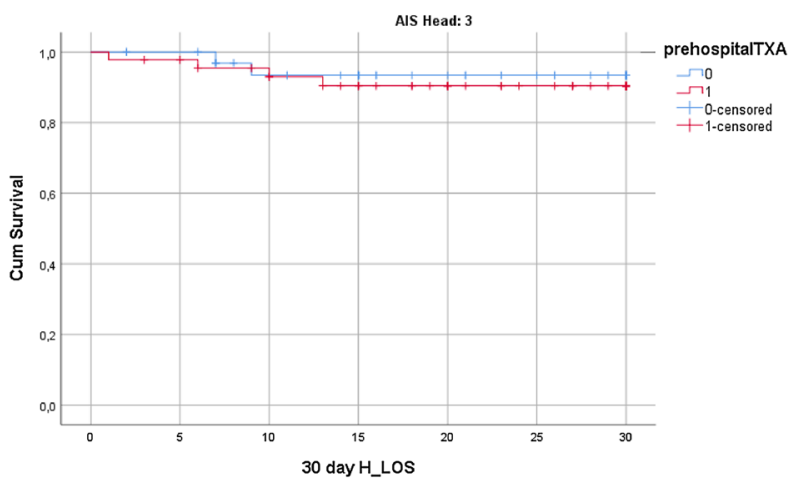

$P=0.65$

C

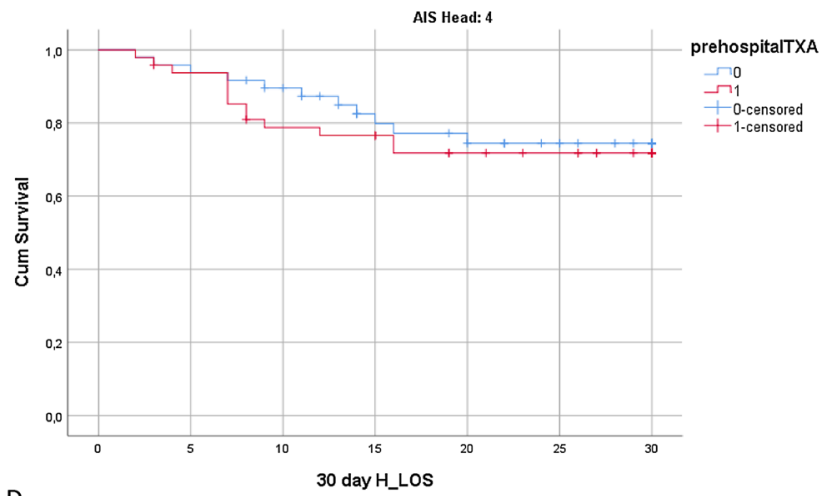

D

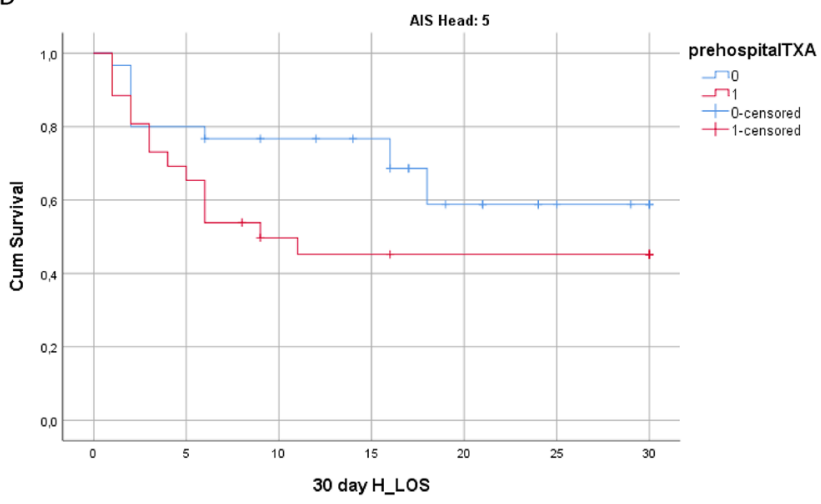


Supplementary Information The online version contains supplementary material available at https://doi.org/10.1007/s00068-021-01827-5.

\section{Acknowledgements none}

Author contributions KW, DJ, and LL have contributed to the conception and design of the study. KW and LL have performed acquisition of data. KW has done the analysis and interpretation of data. KW has drafted the article. LL and DJ have revised it critically for important intellectual content. KW, DJ, and LL have given final approval of the version to be submitted.

Funding No funds were received in connection to the presentd study.

Data availability The dataset supporting the conclusions of this article is available upon reasonable request from the corresponding author.

\section{Declarations}

Conflict of interest All authors declare that they have no conflict of interest.

Ethical approval The local ethics committee approved this prospective observational study (reference number WAG/mb/16/026664).

Consent for publication not applicable

\section{References}

1. Jochems D, Leenen LPH, Hietbrink F, Houwert RM, van Wessem KJP. Increased reduction in exsanguination rates leaves brain injury as the only major cause of death in blunt trauma. Injury. 2018;49(9):1661-7. https://doi.org/10.1016/j.injury. 2018.05.012 (Epub 2018 May 23 PMID: 29903577).

2. Narayan RK, Maas AI, Servadei F, Skolnick BE, Tillinger MN, Marshall LF, Traumatic Intracerebral Hemorrhage Study Group. Progression of traumatic intracerebral hemorrhage: a prospective observational study. J Neurotrauma. 2008;25(6):629-39. https://doi.org/10.1089/neu.2007.0385 (PMID: 18491950).

3. Ramirez RJ, Spinella PC, Bochicchio GV. Tranexamic acid update in trauma. Crit Care Clin. 2017;33(1):85-99. https://doi.org/10. 1016/j.ccc.2016.08.004 (PMID: 27894501).

4. CRASH-2 trial collaborators, Shakur H, Roberts I, Bautista R, Caballero J, Coats T, Dewan Y, El-Sayed H, Gogichaishvili T, Gupta S, Herrera J, Hunt B, Iribhogbe P, Izurieta M, Khamis H, Komolafe E, Marrero MA, Mejía-Mantilla J, Miranda J, Morales C, Olaomi O, Olldashi F, Perel P, Peto R, Ramana PV, Ravi RR, Yutthakasemsunt S. Effects of tranexamic acid on death, vascular occlusive events, and blood transfusion in trauma patients with significant haemorrhage (CRASH-2): a randomised, placebocontrolled trial. Lancet. 2010;376(9734):23-32. https://doi.org/ 10.1016/S0140-6736(10)60835-5 (Epub 2010 Jun 14 PMID: 20554319)

5. CRASH-2 Collaborators, Intracranial Bleeding Study. Effect of tranexamic acid in traumatic brain injury: a nested randomised, placebo controlled trial (CRASH-2 Intracranial Bleeding Study). BMJ. 2011;343:3795. https://doi.org/10.1136/bmj.d3795 (PMID: 21724564; PMCID: PMC3128457).

6. CRASH-3 trial collaborators. Effects of tranexamic acid on death, disability, vascular occlusive events and other morbidities in patients with acute traumatic brain injury (CRASH-3): a randomised, placebo-controlled trial. Lancet. 2019;394:1713-23.

7. Brenner A, Belli A, Chaudhri R, Coats T, Frimley L, Jamaluddin SF, Jooma R, Mansukhani R, Sandercock P, Shakur-Still H, Shokunbi T, Roberts I, CRASH-3 trial collaborators. Understanding the neuroprotective effect of tranexamic acid: an exploratory analysis of the CRASH-3 randomised trial. Crit Care. 2020;24(1):560. https://doi.org/10.1186/s13054-020-03243-4 (PMID: 33172504; PMCID: PMC7657351).

8. Yutthakasemsunt $S$, Kittiwatanagul W, Piyavechvirat $P$, Thinkamrop B, Phuenpathom N, Lumbiganon P. Tranexamic acid for patients with traumatic brain injury: a randomized, doubleblinded, placebo-controlled trial. BMC Emerg Med. 2013;13:20.

9. Lawati KA, Sharif S, Maqbali SA, Rimawi HA, Petrosoniak A, Belley-Cote EP, Sharma SV, Morgenstern J, Fernando SM, Owen JJ, Zeller M, Quinlan D, Alhazzani W, Rochwerg B. Efficacy and safety of tranexamic acid in acute traumatic brain injury: a systematic review and meta-analysis of randomized-controlled trials. Intensive Care Med. 2021;47(1):14-27. https://doi.org/10.1007/ s00134-020-06279-w (Epub 2020 Oct 20 PMID: 33079217).

10. Rowell SE, Meier EN, McKnight B, Kannas D, May S, Sheehan K, Bulger EM, Idris AH, Christenson J, Morrison LJ, Frascone RJ, Bosarge PL, Colella MR, Johannigman J, Cotton BA, Callum J, McMullan J, Dries DJ, Tibbs B, Richmond NJ, Weisfeldt ML, Tallon JM, Garrett JS, Zielinski MD, Aufderheide TP, Gandhi RR, Schlamp R, Robinson BRH, Jui J, Klein L, Rizoli S, Gamber M, Fleming M, Hwang J, Vincent LE, Williams C, Hendrickson A, Simonson R, Klotz P, Sopko G, Witham W, Ferrara M, Schreiber MA. Effect of out-of-hospital tranexamic acid vs placebo on 6-month functional neurologic outcomes in patients with moderate or severe traumatic brain injury. JAMA. 2020;324(10):961-74. https://doi.org/10.1001/jama.2020.8958 (Erratum.In:JAMA.2020Oct27;324(16):1683.PMID:328973 44;PMCID:PMC7489866).

11. Mojallal F, Nikooieh M, Hajimaghsoudi M, Baqherabadi M, Jafari M, Esmaeili A, Karimi NM, Zarepur E. The effect of intravenous tranexamic acid on preventing the progress of cerebral hemorrhage in patients with brain traumatic injuries compared to placebo: a randomized clinical trial. Med J Islam Repub Iran. 2020;27(34):107. https://doi.org/10.34171/mjiri.34.107 (PMID: 33315982;PMCID:PMC7722959).

12. Yokobori S, Yatabe T, Kondo Y, Kinoshita K, Japan Resuscitation Council (JRC) Neuroresuscitation Task Force and the Guidelines Editorial Committee. Efficacy and safety of tranexamic acid administration in traumatic brain injury patients: a systematic review and meta-analysis. J Intensive Care. 2020;8:46. https://doi. org/10.1186/s40560-020-00460-5 (PMID: 32637122; PMCID: PMC7333334).

13. Bossers SM, Loer SA, Bloemers FW, Den Hartog D, Van Lieshout EMM, Hoogerwerf N, van der Naalt J, Absalom AR, Peerdeman SM, Schwarte LA, Boer C, Schober P, BRAIN-PROTECT collaborators. Association between prehospital tranexamic acid administration and outcomes of severe traumatic brain injury. JAMA Neurol. 2020. https://doi.org/10.1001/jamaneurol.2020. 4596 (Epub ahead of print. PMID: 33284310).

14. Gunning AC, Lansink KWW, van Wessem KJP, Balogh ZJ, Rivara FP, Maier RV, Leenen LPH. Demographic patterns and outcomes of patients in level-1 trauma centers in three international trauma systems. World J Surg. 2015;39(11):2677-84.

15. Sauaia A, Moore FA, Moore EE. Early predictors of postinjury multiple organ failure. Arch Surg. 1994;129:39-45.

16. Ranieri VM, Rubenfeld GD, Thompson BT, ARDS Definition Task Force, et al. Acute respiratory distress syndrome: the Berlin definition. JAMA. 2012;307(23):2526-33. 
17. Volovici V, Haitsma IK. Letter: tranexamic acid and severe traumatic brain injury: the futile search for causality? Neurosurgery. 2021;8:nyab034. https://doi.org/10.1093/neuros/nyab034 (Epub ahead of print. PMID: 33555022).

18. van Wessem KJP, Leenen LPH. Does liberal prehospital and in-hospital tranexamic acid influence outcome in severely injured patients? A prospective cohort study. World J Surg. 2021;45(8):2398-407. https://doi.org/10.1007/s00268-02106143-y (Epub 2021 Apr 29).
19. Beks RB, Bhashyam AR, Houwert RM, van der Velde D, van Heijl M, Smeeing DPJ, Hietbrink F, Leenen LPH, Groenwold RHH. When observational studies are as helpful as randomized trials: examples from orthopedic trauma. J Trauma Acute Care Surg. 2019;87(3):730-2.

20. King KL, Balogh ZJ. Invited commentary: a decade older polytrauma patients do as well without as the younger ones with tranexamic acid. World J Surg. 2021. https://doi.org/10.1007/ s00268-021-06253-7 (Epub ahead of print). 